\title{
Application of Hot Melt Extrusion in Pharmaceutical 3D Printing
}

\section{Sonal kushwaha*}

National University, Lightwave Ave, San Diego, CA, USA

\begin{abstract}
$3 \mathrm{D}$ printing is one of the rapid prototyping technology, which produces 3D products using layer-by-layer process from digital designs. 3D printing has gained a lot of attention in pharmaceutical industries since FDA approved a 3D-printed SPRITAM ${ }^{\circledR}$ (levitracetam $1000 \mathrm{mg}$ ) fast dissolving tablets for the adjunct treatment of myoclonic seizures and primary generalized tonic-clonic seizures. There are various 3D printing methods employed for the drug product manufacturing which are used based on the materials, equipment, and solidification. Hot melt extrusion (HME) is one of the techniques which is used for 3D printing. This review article discusses the application of HME in 3D printing of pharmaceutical products. Uniting Hot melt extrusion (HME) for 3D printing with solid freeform fabrication (SFF) such as Fluid deposition method (FDM) offer great chances for designing a wide variety of drug delivery systems.
\end{abstract}

Keywords: 3D printing; Prototype; Solid freeform fabrication

\section{Introduction}

$3 \mathrm{D}$ printing is one of the rapid prototyping technology, which produces $3 \mathrm{D}$ products using layer-by-layer process from digital designs $[1,2]$. This technology developed by merging chemistry, optics and robotics research. 3D printing technologies in health care is mainly focused on oral delivery, tissue engineering, dental, and orthopaedic areas. 3D printing has gained a lot of attention in pharmaceutical industries since FDA approved a 3D-printed SPRITAM (levitracetam $1000 \mathrm{mg}$ ) fast dissolving tablets for the adjunct treatment of myoclonic seizures and primary generalized tonic-clonic seizures. FDA also encourages the development of advanced manufacturing technologies of $3 \mathrm{D}$ printing which can be useful for producing tissue cultures and medical devices [3-5]. 3D printing is used to design complex products, personalized products and products as per the demand, which facilitates in improving the safety, efficacy, and accessibility of medicines [6]. Hot melt extrusion (HME) is the process of melting polymer and drug at high temperature and pressure in the instrument and continuously blend them and force the blend through its orifice. HME is mostly used in the plastic, rubber and food industries. HME is a new emerging research area for health care industries where it is used to improve the oral bioavailability of active pharmaceutical ingredients (APIs) and preparation of precursors for thermoplastic drug eluting devices such as subcutaneous and intraocular implants. This review article discusses the application of HME in 3D printing of pharmaceutical products [7].

\section{Procedure, Advantages and challenges of 3D printing}

The basic steps involved in the production of finished products by $3 \mathrm{D}$ printing are digitally rendered designs using CAD software. These designs are converted to STL format which transfers layer by layer instructions digitally to the printers. The processed raw materials (binder solutions, granules or filaments) are added, and then the print head is moved (within the $\mathrm{x}$ - and $\mathrm{y}$-axes) on the temperature-controlled platform (on the z-axis) to create 3D structures layer-by- layer by fusing the layers together producing desired products which are removed for the post processing (drying, sintering or polishing) [1,8,9].

$3 \mathrm{D}$ printing is used to produce products like highly porous products (orally disintegrating), toroidal products (approximately zero-order release), Complex drug-device combination products, personalized dosing (for potent drugs and children), drug-loaded implants (matching the anatomy of individual patients), polypills (combination of different drugs) and ocular implant. 3D printing facilitates personalization by changing the digital designs which is more feasible than changing equipment design with less operational cost [10-12]. 3D printing is synonymously used with additive manufacturing and rapid prototyping technology. There was a demand for usage of standard terminology by "The American society of mechanical engineers" to adopt additive manufacturing as preferred over 3D printing. Additive manufacturing term is used for a group of technologies which construct the physical parts layer by layer addition of materials which is different from the conventional machining. There are various 3D printing methods employed for drug product manufacturing which are used based on the materials, equipment, and solidification shown in Figure 1 and Table 1 [13-30].

\section{Application of HME in 3D printing}

HME is used to prepare solid solutions/dispersions for drug delivery systems such as pellets and granules, it can reduce the number of processing steps in dosage form manufacturing and can be automated as a continuous process to give better drug homogeneity, capabilities of sustained, modified, and targeted release. Uniting Hot melt extrusion (HME) with solid freeform fabrication (SFF) such as Fluid deposition method (FDM) offer great chances for designing a wide variety of drug delivery systems by $3 \mathrm{D}$ printing technology $[31,32]$.

The different shapes of oral drug delivery systems can be produced by $3 \mathrm{D}$ printing coupled with HME with good drug load (when used with appropriate excipients and hoppers to avoid the drug loss by sticking or degradation of the drug due to higher temperature), which is not possible by conventional method. Dissolution tests shows that geometry plays a major role in drug release characteristics, surface area of the tablets was kept constant, and drug release rates were in the following order (fastest first); pyramid $>$ torus $>$ cube $>$ sphere and cylinder. In easily swallowed dosage forms that reach stomach due to swelling, the tetrahedron shaped dosage forms retained for longer time in the stomach than other shapes of similar size [33].

*Corresponding author: Sonal kushwaha, National University, Lightwave Ave, San Diego, CA 92123, USA, Tel: 858-353-2765; E-mail: sonal.mourya1990@gmail.com

Received May 28, 2018; Accepted June 11, 2018; Published June 18, 2018

Citation: Kushwaha S (2018) Application of Hot Melt Extrusion in Pharmaceutical 3D Printing. J Bioequiv Availab 10: 54-57. 378. doi: 10.4172/0975-0851.1000379

Copyright: (c) 2018 Kushwaha S. This is an open-access article distributed under the terms of the Creative Commons Attribution License, which permits unrestricted use, distribution, and reproduction in any medium, provided the original author and source are credited. 
Citation: Kushwaha S (2018) Application of Hot Melt Extrusion in Pharmaceutical 3D Printing. J Bioequiv Availab 10: 54-57. 378. doi: 10.4172/09750851.1000379

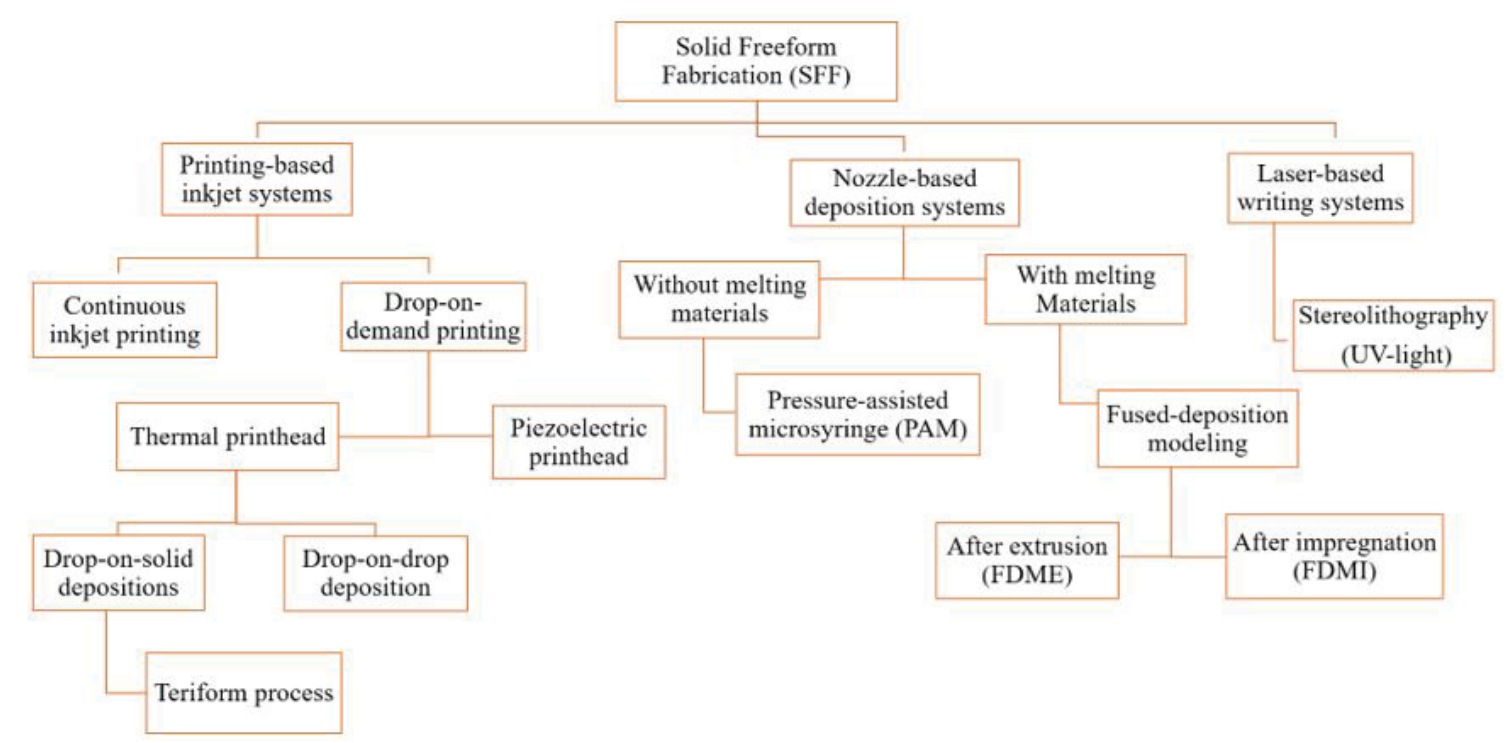

Figure 1: Various pharmaceutical 3D printing techniques.

\begin{tabular}{|c|c|c|c|}
\hline Type of 3D process/technique & Dosage form & Active ingredient/polymer & Author \\
\hline Stereolithography (SLA) & Hydrogel & Ibuprofen, Riboflavin, Polyethylene Glycol, Diacrylate & Martinez et al. [18] \\
\hline FDM 3D printing & Tablet & Felodipine, PEG, PEO, Tween 80, Eudragit EPO & Alhijjaj et al. [19] \\
\hline UV inkjet 3D printed & Tablet & $\begin{array}{l}\text { Ropinirole, cross-linked poly (ethylene glycol diacrylate) } \\
\text { (PEGDA) }\end{array}$ & Clark et al. [20] \\
\hline $\begin{array}{l}\text { semi-solid extrusion 3D printing technique in } \\
\text { combination with UV- LED crosslinking }\end{array}$ & Tablet & Prednisolone, polydimethylsiloxane (PDMS) & Hollander et al. [21] \\
\hline (FDM) and (SLA) & $\begin{array}{l}\text { Model of a nose adapted to the } \\
\text { morphology of an individual }\end{array}$ & FPLA-salicylic acid and PCL- salicylic acid & Goyanes et al. [22] \\
\hline FDM & Tablet & Haloperidol & Solanki et al. [23] \\
\hline Thermal Inkjet (TIJ) Printing & Solid dosage forms & Rasagiline mesylate & Genina et al. [24] \\
\hline (FDM) and Hot Melt Extrusion (HME) & Tablet & Domperidone, Hydroxypropyl cellulose (HPC) & Chai et al. [25] \\
\hline FDM & Nanocapsules & Deflazacort, Poly(ع-caprolactone) (PCL) & Beck et al. [26] \\
\hline FDM and HME & Compartmentalized shells & Rifampicin (Rif) And Isoniazid (ISO) & Genina et al. [27] \\
\hline FDM & Tablet & Hydrochlorothiazide & Sadia et al. [28] \\
\hline 3D printed & Biodegradable patch & $\begin{array}{l}\text { Poly(Lactide-Co-Glycolide), Polycaprolactone, and } \\
\text { 5-Fluorouracil }\end{array}$ & Yi et al. [29] \\
\hline FDM and $\mathrm{HME}$ & Subcutaneous rods & Indomethacin, Ethylene Vinyl Acetate (Eva) Copolymers & Genina et al. [30] \\
\hline FMD and $\mathrm{HME}$ & Three-compartment hollow cylinder & $\begin{array}{l}\text { Polymer Polyvinyl Alcohol (Pva), Mannitol and } \\
\text { Hydrochlorothiazide (Hctz), Polylactic Acid (Pla) }\end{array}$ & $\begin{array}{l}\text { GGioumouxouzis et } \\
\text { al. [31] }\end{array}$ \\
\hline FDM & Tablet & $\begin{array}{l}\text { Nitrofurantoin, Polylactic Acid and Hydroxypropyl } \\
\text { Methylcellulose }\end{array}$ & Boetker et al. [32] \\
\hline FDM and $\mathrm{HME}$ & $\begin{array}{l}\text { T-shaped prototypes of intrauterine } \\
\text { system (IUS) }\end{array}$ & Indomethacin, Poly(E-Caprolactone) & Hollander et al. [21] \\
\hline (HME) with 3D printing (3DP) & $\begin{array}{l}\text { 3D-printed-cube, pyramid, cylinder, } \\
\text { sphere and torus }\end{array}$ & Paracetamol loaded filaments of Polyvinyl alcohol & Goyanes et al. [33] \\
\hline
\end{tabular}

Table 1: Current 3D Printing technologies to prepare pharmaceutical formulations.

FDM 3D Printing with HME and fluid bed coating combination is used to achieve appropriate dissolution kinetics of budesonide by loading into polyvinyl alcohol filaments using HME. The filaments were shaped into capsule-shaped tablets (caplets) using an FDM $3 \mathrm{D}$ printer; these caplets were then coated with a layer of enteric polymer using fluid bed. The only disadvantage was low drug load of budesonide, which was due to adherence of drug to the walls of the container on transfer to the hopper and barrel during extrusion, and due to irregular extrusion of components. The drug loading is increased by improve mixing and altering shear force and pressure within the barrel $[32,33]$.
In 3D printer with HME enables production of oral drug delivery devices with multilayer device and DuoCaplet, which is difficult to manufacture by powder compaction. This type of oral drug delivery devices shows definitive separation between the different drug layers and modulate drug dissolution profiles of drugs or targeting to different regions of gastrointestinal tract. Coupling of 3D printing with HME produced filaments of Flex EcoPLA (FPLA)-salicylic acid and Polycaprolactone (PCL)-salicylic acid with uniform diameter. The drug loading in case of PCL was to be more compared to FLPA, due to degradation of salicylic acid at higher temperature during HME and 3D printing. In such cases the temperature of extrusion can be decreased 
Citation: Kushwaha S (2018) Application of Hot Melt Extrusion in Pharmaceutical 3D Printing. J Bioequiv Availab 10: 54-57. 378. doi: 10.4172/09750851.1000379

in HME by using different polymers, which would help in reducing the $3 \mathrm{D}$ printing temperature [5].

In $3 \mathrm{D}$ printing of tablet with typical volumetric flow rate for extrusion for printing a tablet of mass of $500 \mathrm{mg}$ and a specific gravity of 1.0 would require at least $3 \mathrm{~min}$ of production time per nozzle. In comparison, a tablet press operating at $30 \mathrm{rpm}$ compresses one tablet per punch-and-die-set every 2 s, independent of tablet size. There is a need for increasing printing speed relative to traditional processes, the recent advances are racetrack printing, this eliminates print head movement and moves the print bed with constant speed. Also, products can be printed using rotating platforms, which prints at various angles by removing the requirement of support material.

The process of drug loading is expensive and time consuming, drug loading is by passive diffusion technique in $3 \mathrm{D}$ printing, it requires concentrated solutions. Also requires drug to be thermostable and solvent should neither dissolve, nor damage integrity of polymeric filament. Hence, it requires to develop an alternative manufacturing approach, the best one would be coupling of FDM 3D printing and HME. There is need new bio-compatible/biodegradable polymers, which melts at lower temperatures or they could chemically functionalize polymeric filaments to increase drug loading and to avoid the potential instability of the incorporated drug [12,31-33].

Usually the temperature needed for printing is generally higher than for extrusion of filaments. Problems of nozzle clogging following increase in the melt viscosity is observed, which can be reduced by modulating the FDM processing temperature. The temperature of material flowing out of the chamber should be able to compensate for the sudden cooling occurring when out of the nozzles, which would be an obstacle for layer adherence with another layer on the platform [33].

The rheological behavior of molten drug-polymer mixtures from the HME should be optimized for different printing processes. The rheological experiments performed at the HME temperature, $180^{\circ} \mathrm{C}$, which is lower than the printing temperature will help in minimize possible thermal degradation during printing by modulating the residence time. There is increase in porosity of undried sample due to evaporation of the higher moisture content in the sample during extrusion and $3 \mathrm{D}$ printing. To limit the possible variables which affect the dissolution properties of the 3D printed geometries, the samples has to be dried prior to hot-melt extrusion and subsequent $3 \mathrm{D}$ printing. Thus, it would be helpful to predict whether adjusting of the nozzle temperature or speed required to match flow properties [33].

\section{Conclusion}

Hot melt extrusion with 3D printing is powerful technique which is helpful to design the modified drug-delivery systems. In future, there is a need to explore about HME with 3D printing for pharmaceutical manufacturing.

\section{References}

1. Kushwaha AS, Repka MA, Murthy SN (2017) A novel apremilast nail lacquer formulation for the treatment of nail psoriasis. AAPS Pharm Sci Tech 18: 29492956.

2. Horst DJ (2018) 3D Printing of Pharmaceutical Drug Delivery Systems. Lupine Publishers.

3. Goyanes A, Chang H, Sedough D, Hatton GB, Wang J, et al. (2015) Fabrication of controlled-release budesonide tablets via desktop (FDM) 3D printing. Int J Pharm 496: 414-420.

4. Kushwaha A, Shivakumar HN, Murthy SN (2016) lontophoresis for drug delivery into the nail apparatus: exploring hyponychium as the site of delivery. Drug Dev Ind Pharm 42: 1678-1682.
5. Kushwaha AS, Sharma P, Shivakumar HN, Rappleye C, Zukiwski A, et al (2017) Trans-ungual Delivery of AR-12, a Novel Antifungal Drug. AAPS Pharm Sci Tech 18: 2702-2705

6. Jonathan G, Karim A (2016) 3D printing in pharmaceutics: A new tool for designing customized drug delivery systems. Int J Pharm 499: 376-394.

7. https://www.particlesciences.com/docs/technical_briefs/TB_2011_3.pdf

8. Goyanes A, Wang J, Buanz A, Martinez-Pacheco R, Telford R, et al. (2015) 3D Printing of Medicines: Engineering Novel Oral Devices with Unique Design and Drug Release Characteristics. Mol Pharma 12: 4077-4084.

9. Goyanes A, Det-Amornrat U, Wang J, Basit AW, Gaisford S (2016) 3D scanning and $3 D$ printing as innovative technologies for fabricating personalized topical drug delivery systems. J Controlled Release 234: 41-48.

10. Melocchi A, Parietti F, Maroni A, Foppoli A, Gazzaniga A, et al. (2016) Hot-melt extruded filaments based on pharmaceutical grade polymers for 3D printing by fused deposition modeling. Int J Pharma 509: 255-263.

11. Manda P, Kushwaha AS, Kundu S, Shivakumar HN, Jo SB, et al. (2016) Delivery of ziconotide to cerebrospinal fluid via intranasal pathway for the treatment of chronic pain. J Control Release 224: 69-76.

12. Boetker J, Water JJ, Aho J, Arnfast L, Bohr A, et al. (2016) Modifying release characteristics from 3D printed drug-eluting products. Eur J Pharma Sci 90: 47-52.

13. Goyanes A, Martinez PR, Buanz A, Basit AW, Gaisford S (2015) Effect of geometry on drug release from 3D printed tablets. Int J Pharma 494: 657-663.

14. Kushwaha A, Murthy RN, Murthy SN, Elkeeb R, Hui X, et al. (2015) Emerging therapies for the treatment of ungual onychomycosis. Drug Dev Ind Pharm 41: 1575-1581.

15. Martinez PR, Goyanes A, Basit AW, Gaisford S (2017) Fabrication of drugloaded hydrogels with stereo lithographic 3D printing. Int J Pharm 532: 313317.

16. Alhijjaj M, Belton P, Qi S. An investigation into the use of polymer blends to improve the printability of and regulate drug release from pharmaceutical solid dispersions prepared via fused deposition modeling (FDM) 3D printing. Eur $\mathrm{J}$ Pharm and Biopharm 108: 111-125.

17. Clark EA, Alexander MR, Irvine DJ, Roberts CJ, Wallace MJ, et al. (2017) 3D printing of tablets using inkjet with UV photo initiation. Int J Pharm 529: 523530 .

18. Hollander J, Genina N, Jukarainen H, Khajeheian M, Rosling (2016) 3D printed UV light cured poly dimethylsil oxane devices for drug delivery. Int $\mathrm{J}$ pharm 5173: 31071-31072.

19. Goyanes A, Det-Amornrat U, Wang J, Basit AW, Gaisford S (2016) 3D scanning and $3 D$ printing as innovative technologies for fabricating personalized topical drug delivery systems. J Cont Rel 234: 41-48.

20. Solanki NG, Tahsin M, Shah AV, Serajuddin ATM (2018) Formulation of 3D Printed Tablet for Rapid Drug Release by Fused Deposition Modeling: Screening Polymers for Drug Release, Drug-Polymer Miscibility and Printability. J Pharm Sci 107: 390-401.

21. Genina N, Janßen EM, Breitenbach A, Breitkreutz J, Sandler N (2013) Evaluation of different substrates for inkjet printing of rasagiline mesylate. Eur J Pharm Biopharm 85: 1075-1083.

22. Chai $X$, Chai H, Wang X, Yang J, Li J, et al. (2017) Fused Deposition Modeling (FDM) 3D Printed Tablets for Intragastric Floating Delivery of Domperidone. Scientific Reports 7: 2829.

23. Beck RCR, Chaves PS, Goyanes A, Vucosavljevic B, Buanz A, et al. (2017) 3D printed tablets loaded with polymeric nanocapsules: An innovative approach to produce customized drug delivery systems. Int J Pharma 528: 268-279.

24. Genina N, Boetker JP, Colombo S, Harmankaya N, Rantanem J, et al. (2017) Anti-tuberculosis drug combination for controlled oral delivery using 3D printed compartmental dosage forms: From drug product design to in vivo testing. $J$ Cont Release 268: 40-48.

25. Sadia M, Arafat B, Ahmed W, Forbes RT, Ahlnan MA (2018) Channelled tablets: An innovative approach to accelerating drug release from 3D printed tablets. J Cont Rel 269: 355-363.

26. Yi HG, Choi YJ, Kang KS, Hong JM, Pati RG, et al. (2016) A 3D-printed local drug delivery patch for pancreatic cancer growth suppression. J Cont Rel 238 231-241. 
Citation: Kushwaha S (2018) Application of Hot Melt Extrusion in Pharmaceutical 3D Printing. J Bioequiv Availab 10: 54-57. 378. doi: 10.4172/09750851.1000379

27. Genina N, Hollander J, Jukarainen H, Makila E, Salonen J (2016) Ethylene vinyl acetate (EVA) as a new drug carrier for 3D printed medical drug delivery devices. Eur J Pharm Sci 90: 53-63.

28. Gioumouxouzis Cl, Katsamenis O, Bouropoulos N, Fatouros DG (2017) 3D printed oral solid dosage forms containing hydrochlorothiazide for controlled drug delivery. J Drug Del Sci and Tech 40: 164-171.

29. Boetker J, Water JJ, Aho J, Arnfast L, Bohr A, et al. (2016) Modifying release characteristics from 3D printed drug-eluting products. Eur J Pharm Sci 90: 47-52.

30. Goyanes A, Martinez PR, Buanz A, Basit AW, Gaisford S (2015) Effect of geometry on drug release from 3D printed tablets. Int J Pharm 494: 657-663.

31. Norman J, Madurawe RD, Moore CMV, Khan MA, Khairuzzaman A (2017) A new chapter in pharmaceutical manufacturing: 3D-printed drug products. Advanced Drug Delivery Reviews.

32. Kushwaha AS, Narasimha Murthy S (2017) Pretreatment with Microneedle Array to Improve the Nail Permeability. J Pharm Drug Deliv Res 6: 2.

33. Chhaya MP, Poh PSP, Balmayor ER, Griensven MV, Schantz JT, et al. Additive manufacturing in biomedical sciences and the need for definitions and norms. Expert Review of Medical Devices. 